Article

\title{
Limited Diagnostic Utility of Chromogranin A Measurements in Workup of Neuroendocrine Tumors
}

\author{
Jonas Baekdal 1,2,*, Jesper Krogh 1,2, Marianne Klose 1,2, Pernille Holmager 1,2, \\ Seppo W. Langer 1,3, Peter Oturai 1,4,5, Andreas Kjaer 1,4,5 ${ }^{1}$, Birgitte Federspiel 1,6, \\ Linda Hilsted ${ }^{1,7}$, Jens F. Rehfeld ${ }^{1,7}$, Ulrich Knigge 1,2,8 and Mikkel Andreassen 1,2 ${ }^{\mathbb{D}}$ \\ 1 ENETS Neuroendocrine Tumor Centre of Excellence, Rigshospitalet, Copenhagen University Hospital, \\ 2100 Copenhagen, Denmark; jesper.krogh@dadlnet.dk (J.K.); marianne.christina.klose.01@regionh.dk (M.K.); \\ pernille.holmager.01@regionh.dk (P.H.); Seppo.Langer@regionh.dk (S.W.L.); \\ Peter.Sandor.Oturai@regionh.dk (P.O.); akjaer@sund.ku.dk (A.K.); birgitte.federspiel@regionh.dk (B.F.); \\ linda.maria.hilsted@regionh.dk (L.H.); Jens.F.Rehfeld@regionh.dk (J.F.R.); \\ Ulrich.Peter.Knigge@regionh.dk (U.K.); mikkel.andreassen.01@regionh.dk (M.A.) \\ 2 Department of Endocrinology, Rigshospitalet, Copenhagen University Hospital, 2100 Copenhagen, Denmark \\ 3 Department of Oncology, Rigshospitalet, Copenhagen University Hospital, 2100 Copenhagen, Denmark \\ 4 Department of Clinical Physiology, Nuclear Medicine \& PET and Cluster for Molecular Imaging, \\ Copenhagen University Hospital, 2100 Copenhagen, Denmark \\ 5 Department of Biomedical Sciences, Rigshospitalet and University of Copenhagen, \\ 2100 Copenhagen, Denmark \\ 6 Department of Pathology, Rigshospitalet, Copenhagen University Hospital, 2100 Copenhagen, Denmark \\ 7 Department of Clinical Biochemistry, Rigshospitalet, Copenhagen University Hospital, \\ 2100 Copenhagen, Denmark \\ 8 Department of Surgery and Transplantation, Rigshospitalet, Copenhagen University Hospital, \\ 2100 Copenhagen, Denmark \\ * Correspondence: jonas.a.baekdal@gmail.com; Tel.: +45-6013-4687
}

Received: 11 October 2020; Accepted: 28 October 2020; Published: 29 October 2020 updates

\begin{abstract}
Background: Plasma chromogranin A ( $\mathrm{CgA})$ is related to tumor burden and recommended in the follow-up of patients diagnosed with neuroendocrine tumors (NETs). The use of CgA in the workup of a suspected NET is more questionable. Objective: To assess the positive predictive value (PPV) of CgA plasma concentrations above the upper reference limit (URL) in patients with suspected NET. Method: Patients referred to the NET Centre, Rigshospitalet, Copenhagen from 2015 to 2019 with clinically suspected NET were included if a $\mathrm{CgA}$ measurement was performed prior to referral. The utility of $\mathrm{CgA}$ was assessed by comparing pre-referral $\mathrm{CgA}$ concentrations to the outcome of a thorough workup. In 47 selected cases with continuously unexplained elevated $\mathrm{CgA}$ concentrations, a processing-independent analysis (PIA) for CgA was performed. Results: A total of 197 patients were included. NET was ultimately diagnosed in 25 patients. CgA plasma concentrations were above the URL (elevated) in 19/25 patients diagnosed with NET. In total, 167/197 had elevated CgA concentrations at referral. The positive predictive value (PPV) of elevated $\mathrm{CgA}$ concentration was $11 \%$ (19/167). Proton pump inhibitor (PPI) treatment was identified as the possible cause of CgA elevation in 55/148 patients with falsely elevated CgA. CgA concentration was normal in 28/47 patients when using PIA. Conclusion: Our data do not support using measurement of $\mathrm{CgA}$ for screening when NET is suspected since the PPV was rather low. PPI treatment is a common cause of increased CgA concentrations and should always be discontinued before $\mathrm{CgA}$ measurement. PIA of $\mathrm{CgA}$ could be a way of excluding NET when suspicion is based primarily on elevated CgA.
\end{abstract}

Keywords: chromogranin A; neuroendocrine tumor; workup; processing-independent analysis (PIA); positive predictive value (PPV) 


\section{Introduction}

Neuroendocrine neoplasms (NENs) are rare heterogenous tumors which may arise in several different anatomical sites such as small intestine, pancreas and lungs [1]. Well-differentiated tumors are referred to as neuroendocrine tumors (NETs) whereas poorly differentiated NENs are referred to as neuroendocrine carcinomas (NECs). NETs are further divided, according to Ki-67 proliferation index, into low- (G1) (Ki-67 < 3\%), intermediate- (G2) (Ki-67 3-20\%) or high-grade (G3) (Ki-67 > 20\%) [2]. NENs arise from neuroendocrine cells which express markers of neuroendocrine differentiation (e.g., chromogranin A (CgA) and synaptophysin) [3]. Some of these tumors, particularly G1 and G2 NETs, are functional-i.e., able to produce and release bioactive peptides or amines to the bloodstream in contrast to non-functional NETs [4,5]. The release of bioactive peptide and amines causes specific endocrine symptoms related to the specific molecule (e.g., hypergastrinemia due to a gastrinoma), which may lead to an earlier diagnosis compared to non-functional NETs which often present fairly late with distant metastases or mass effect [4,6-9]. Most small intestinal (SI)-NETs produce serotonin and other vasoactive molecules which may cause carcinoid syndrome in the presence of liver metastases $[6,10,11]$. The most frequent symptoms in the carcinoid syndrome are flushing and diarrhea [11].

The CgA protein belongs to the Granin family. It is a precursor protein of 439 amino acids [12]. CgA immunoreactivity is found abundantly in neuroendocrine cells and increased plasma concentrations of CgA have been associated with most NETs [5,13,14]. However, a wide range of non-NET conditions are associated with elevated plasma CgA concentrations such as chronic atrophic gastritis, renal and hepatic dysfunction, cardiovascular disease, and rheumatologic disease. In addition, proton pump inhibitor (PPI) treatment is a common cause of CgA elevation [5,15]. On the other hand, not all NETs give rise to elevated plasma $\mathrm{CgA}$. Important factors determining $\mathrm{CgA}$ concentrations are NET type, secretory activity and extent of disease $[5,16,17]$. Furthermore, diagnostic sensitivity and specificity depend on the assay type, analytic specificity and sensitivity of the antiserum employed [14], as does the fact that the CgA protein is heavily processed to smaller fragments [14,18-20].

In the ENETS (European Neuroendocrine Tumor Society) guidelines [21], measurement of CgA is recommended during follow-up of patients diagnosed with NET since plasma concentrations are related to tumor burden $[14,18]$ and an increase in plasma concentration of $\mathrm{CgA}$ may be a predictor of disease progression [22,23]. Despite the diagnostic pitfalls, some guidelines [24-26] also recommend the use of plasma $\mathrm{CgA}$ in diagnosis of NETs, although no clinical data directly support this strategy. Therefore, we investigated the positive predictive value (PPV) and diagnostic utility of plasma CgA in patients referred to our NET Centre of Excellence for a thorough NET workup.

\section{Methods}

\subsection{Patients}

Patients were recruited from ENETS Centre of Excellence, Rigshospitalet, Copenhagen University Hospital. The NET Centre receives patients from eastern Denmark, which has roughly 2.7 million inhabitants. Patients referred from 1 January 2015 to 31 December 2019 with clinically suspected or histologically verified NET were included if plasma CgA measurements had been performed prior to referral and histological diagnosis. Exclusion criteria were: pre-referral plasma CgA concentration measured using another assay than our in-house CgA assay [18], pre-referral CgA measurement performed after histological verification of NET, and incomplete NET workup at the time of data collection.

We collected data on age, gender, medical history, medication, renal function, pre- and post-referral $\mathrm{CgA}$ concentrations and outcome of examinations including imaging and pathology reports from patients' files.

The patients referred with a NET histologically verified prior to referral all had a Ki-67 $<20 \%$ corresponding to G1 or G2 NET. G3 NET and NEC patients [2] were referred to the 
Department of Oncology and therefore were not among the included patients. Patients with suspected NET of the pituitary, thyroid gland (medullary thyroid cancer), parathyroid glands and adrenals (paragangliomas and pheochromocytomas) were referred to our endocrine unit and were not included in the study.

The study was approved by the local data protection agency at Rigshospitalet (no. P-2019-225) and by the Danish Patient Safety Authority (no. 3-3013-3093/1). Due to the retrospective design informed consent was not required.

\section{2. $\mathrm{Cg} A_{340-348}$ Radioimmunassay}

All measurements of plasma CgA concentration pre- and post-referral were performed using an in-house $\mathrm{CgA}_{340-348}$ radioimmunoassay (RIA) ( $\left.\mathrm{CgA}_{340-348}\right)$. Upper reference limit (URL) is $130 \mathrm{pmol} / \mathrm{L}$, based on a study population of 88 apparently healthy individuals of both sexes, median age 41 (interquartile range (IQR) 30-51) years [14]. In this assay, the antiserum employed binds an epitope that is located on sequence 340-348 [20]. Inter-assay coefficient of variation (CV) of replicate samples was estimated to $11 \%$ in a range from 7.5 to $100 \mathrm{pmol} / \mathrm{L}$ [18].

\subsection{Processing-Independent Analysis of $\operatorname{Cg} A$}

The post-translational processing of the CgA protein is tissue-specific and varies individually. Therefore, measurement of a single CgA fragment in the post-translational processing cascade may lead to varying results among different patients [19]. To cope with such variability, processing-independent analysis has been developed [27] and also applied to $\operatorname{CgA}[14,18,19,27]$. This method utilizes endoproteolytic cleavage of $\mathrm{CgA}$ by preincubating the sample with trypsin (hereby exposing the epitope at $\mathrm{CgA}_{340-348}$, which does not undergo post-translational processing) and subsequent quantification of $\mathrm{CgA}$ with the $\mathrm{CgA}_{340-348}$ RIA to quantify the entire mRNA translation product regardless of post-translational processing [14,18]. A diagram of CgA processing and fragments is shown in Figure 1. None of the $\mathrm{CgA}$ fragments have better diagnostic accuracy than processing-independent analysis (PIA) of CgA [18].

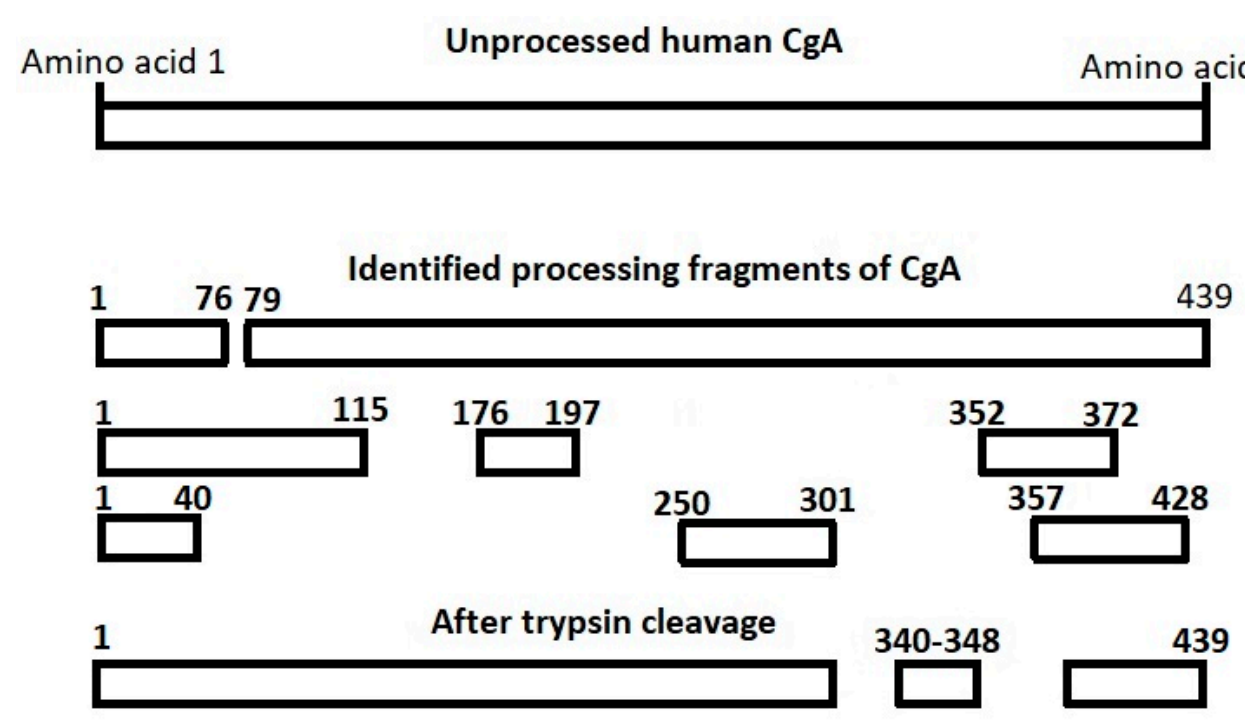

Figure 1. Identified processing products of chromogranin A ( $\mathrm{CgA})$. The fragments have been suggested to be bioactive with different primarily inhibitory effects. The $\mathrm{CgA}_{340-348}$ sequence does not undergo post-translational processing. $\mathrm{CgA}_{340-348}$ is located between tryptic cleavage sites and one $\mathrm{CgA}_{340-348}$ fragment will be released per $\mathrm{CgA}$ molecule when a sample is pre-incubated with trypsin, thus providing an accurate measure of the total $\mathrm{CgA}$ concentration of the sample. 
URL is $1100 \mathrm{pmol} / \mathrm{L}$. This value was based on the same population as the $\mathrm{CgA}_{340-348}$ RIA [14]. From 2017 to 2019, CgA PIA was used in selected cases with unexplained continuously elevated $\mathrm{CgA}$. If $\mathrm{CgA}$ PIA was within normal range, $\mathrm{CgA}_{340-348}$ was considered falsely elevated due to inter-individual variability of $\mathrm{CgA}$ expression and post-translational processing. Readers further interested in processing-independent analysis should study references 14,18 and 19 [14,18,19].

\subsection{Definitions}

All NETs were diagnosed by histological examination of the primary tumor or metastases. If CgA was above the URL and NET was subsequently diagnosed, $\mathrm{CgA}$ was defined as true positive. If the $\mathrm{CgA}$ concentrations were within normal range and NET was diagnosed, $\mathrm{CgA}$ was defined as false negative. Correspondingly, if $\mathrm{CgA}$ was above the URL and no NET was diagnosed, $\mathrm{CgA}$ was defined as false positive and if $\mathrm{CgA}$ was within normal range and no NET was diagnosed, $\mathrm{CgA}$ was defined as true negative.

Subcategories of $\mathrm{CgA}$ elevation were defined: marginally elevated $(1-2 \times \mathrm{URL})$, moderately elevated ( $2-4 \times$ URL), considerably elevated $(4-8 \times \mathrm{URL})$ and severely elevated $(>8 \times \mathrm{URL})$. The intervals were defined before the initiation of data analyses.

Renal dysfunction was defined as estimated glomerular filtration rate (eGFR) $<60 \mathrm{~mL} / \mathrm{min} / 1.73 \mathrm{~m}^{2}$. This cut-off was based on a study showing that non-NET patients with glomerular filtration rate (GFR) $<60 \mathrm{~mL} / \mathrm{min} / 1.73 \mathrm{~m}^{2}$ had significantly increased levels of CgA [28].

Symptoms leading to measurement of $\mathrm{CgA}$ concentrations in plasma were categorized into the following groups: Gastro-intestinal (GI) symptoms (diarrhea, constipation, abdominal pain, dyspepsia, nausea, vomiting), flushing, attack-like phenomena (palpitations, hypertension, dyspnea, symptoms of hypoglycemia or excessive sweating) and unspecific symptoms (night sweat, weight loss, fever, tiredness/fatigue). Other reasons for CgA measurement were examinations suggestive of NET (imaging or endoscopy) and coincidental.

\subsection{Statistics}

Statistical analysis and data collection were performed in IBM SPSS statistics 26. Positive predictive value (PPV) of pre-referral CgA was calculated as: patients diagnosed with NET who had elevated $\mathrm{CgA}$ concentrations in plasma divided by all patients with elevated $\mathrm{CgA}$ concentrations in plasma.

Diagnostic sensitivity was calculated as the number of patients diagnosed with NET who had elevated CgA concentrations divided by the total number of patients diagnosed with NET.

The relationship between risk of NET and CgA plasma concentrations was assessed by a binary logistic regression analysis. Results are presented as odds ratio (OR) per $100 \mathrm{pmol} / \mathrm{L}$ increase in CgA plasma concentration.

When comparing CgA concentrations in patients before and after discontinuation of PPI, non-parametric statistical analysis (Wilcoxon signed rank test) was performed, since the data distribution was not Gaussian (even after logarithmic transformation $(\log 10))$. Reported $p$-values are two-tailed and $p<0.05$ is considered significant.

\section{Results}

\subsection{Baseline Characteristics}

Pre-referral CgA measurements were performed in 229 patients. Of these, 32 were excluded because pre-referral plasma $\mathrm{CgA}$ concentrations were measured using another assay than $\mathrm{CgA}_{340-348}$ $(n=8)$, pre-referral CgA measurements were performed after histological verification of NET $(n=6)$ or NET workup was incomplete at the time of data collection $(n=18)$. Thus, 197 patients were included in the final analysis (shown in Figure 2). 


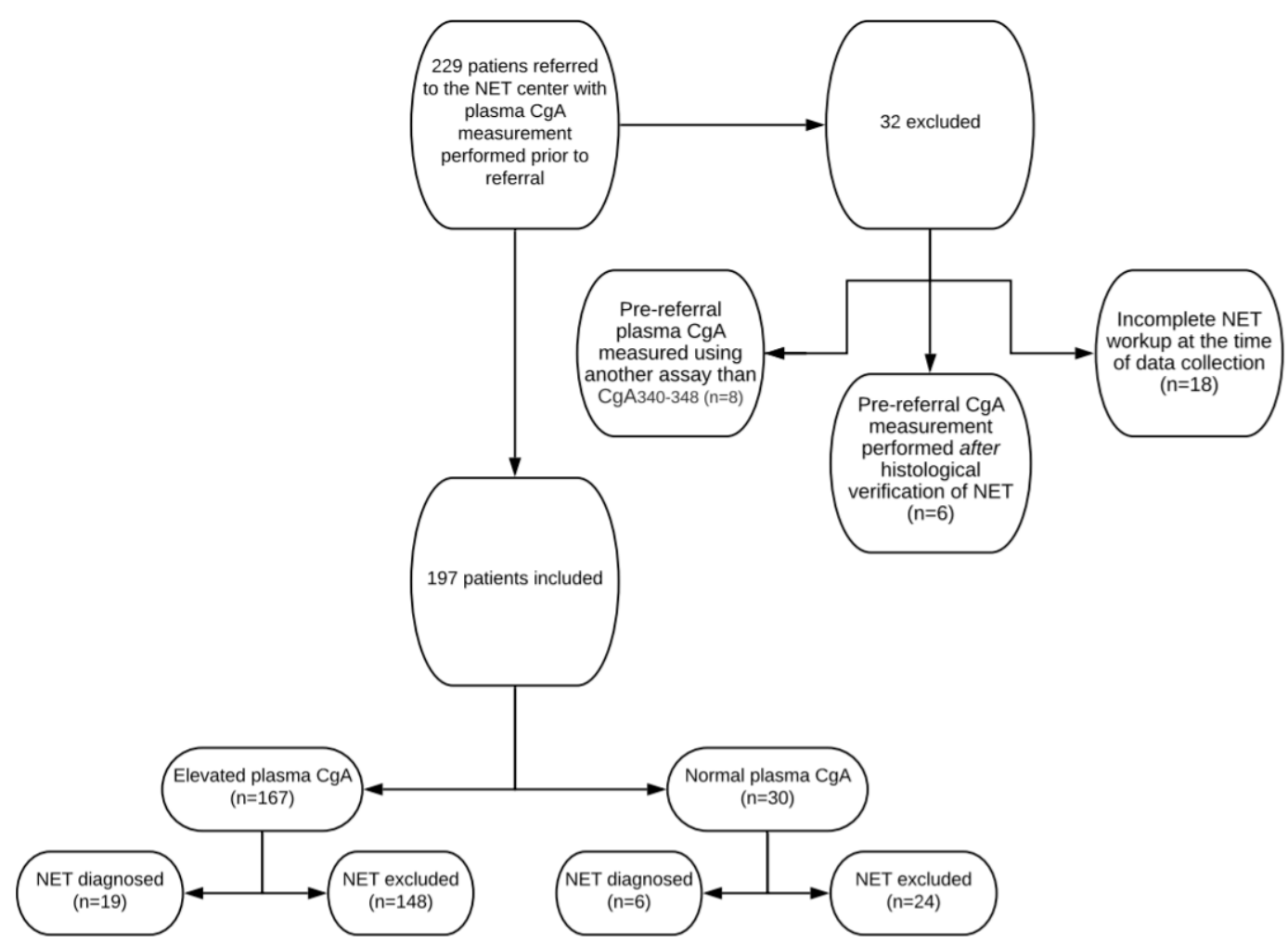

Figure 2. Flowchart of included and excluded patients, pre-referral CgA plasma concentration levels and total number of neuroendocrine tumors diagnosed.

Baseline characteristics are shown in Table 1. Median age was 60 (range 20 to 88) years. Sixty-seven percent were female. Seven patients were referred to the NET Centre with histologically verified NET and 190 were referred with suspected NET for further workup. Plasma CgA concentrations prior to referral were elevated in 167 cases (85\%) and normal in 30 cases (15\%). Sixty-one (31\%) were treated with PPI during the pre-referral measurement of CgA plasma concentrations. The indication for $\mathrm{CgA}$ measurement was based on symptoms in 154 cases (78\%) and an examination suggestive of NET in 36 cases $(18 \%)$ (imaging $n=28$, endoscopy $n=8)$. In seven cases $(3 \%)$, measurement of CgA was coincidental.

Of the seven patients referred with histologically verified NET, five had NET of the small intestine and two had NET of the pancreas.

Diagnostic imaging was performed less than 6 months prior to referral in 123 patients $(60 \%)$ with a total of 145 imaging examinations. In 49 patients (24\%) endoscopic examination was performed less than 6 months prior to referral with a total of 74 endoscopic examinations (shown in Table 2). 
Table 1. Baseline characteristics.

\begin{tabular}{|c|c|c|c|c|c|c|c|}
\hline & & Total & Normal CgA & {$[\mathrm{CgA}] 1-2 \times \mathrm{URL}$} & {$[\mathrm{CgA}] 2-4 \times \mathrm{URL}$} & {$[\mathrm{CgA}] 4-8 \times \mathrm{URL}$} & {$[\mathrm{CgA}]>8 \times \mathrm{URL}$} \\
\hline \multicolumn{2}{|c|}{ Patients included, $n(\%)$} & 197 & $30(15 \%)$ & $91(46 \%)$ & $41(20 \%)$ & $20(10 \%)$ & $15(8 \%)$ \\
\hline \multicolumn{2}{|c|}{ Female, $n(\%)$} & $132(67 \%)$ & 17 & 63 & 29 & 12 & 9 \\
\hline \multicolumn{2}{|c|}{ Age, years, median (IQR) } & $60(49-70)$ & $59(45-70)$ & $56(42-69)$ & $63(56-69)$ & $61(50-69)$ & $71(64-75)$ \\
\hline \multicolumn{2}{|c|}{ PPI-treated, $n(\%)$} & $61(31 \%)$ & 3 & 23 & 22 & 7 & 6 \\
\hline \multirow{2}{*}{\multicolumn{2}{|c|}{$\begin{array}{c}\text { NET at referral, } n \\
\text { Referred for NET workup }, n\end{array}$}} & 7 & 1 & 2 & 0 & 2 & 2 \\
\hline & & 190 & 29 & 89 & 41 & 18 & 13 \\
\hline \multirow{6}{*}{$\begin{array}{c}\text { Main Indication } \\
\text { for } \mathrm{CgA} \\
\text { measurement }\end{array}$} & GI symptoms, $n$ & $65(33 \%)$ & $4(13 \%)$ & $33(36 \%)$ & $18(44 \%)$ & $5(25 \%)$ & $5(33 \%)$ \\
\hline & Attack-Like Phenomena, $n$ & $41(20 \%)$ & $5(17 \%)$ & $22(24 \%)$ & $8(7 \%)$ & $3(15 \%)$ & $2(13 \%)$ \\
\hline & $\begin{array}{c}\text { Examination suggestive of } \\
\text { NET, } n\end{array}$ & $36(18 \%)$ & $17(57 \%)$ & $10(11 \%)$ & $2(5 \%)$ & $4(20 \%)$ & $4(27 \%)$ \\
\hline & Flushing, $n$ & $34(17 \%)$ & $4(13 \%)$ & $17(19 \%)$ & $7(17 \%)$ & $3(15 \%)$ & $3(20 \%)$ \\
\hline & Unspecific symptoms, $n$ & $14(7 \%)$ & 0 & $8(9 \%)$ & $3(7 \%)$ & $2(10 \%)$ & $1(7 \%)$ \\
\hline & Coincidental, $n$ & $7(4 \%)$ & 0 & $1(1 \%)$ & $3(7 \%)$ & $3(15 \%)$ & 0 \\
\hline
\end{tabular}

Total number of included patients, age, number of proton pump inhibitor (PPI)-treated patients, number of patients with neuroendocrine tumor (NET) at referral and indications for CgA measurement grouped according to CgA elevation subcategories.

Table 2. Imaging and endoscopic examinations pre-and post-referral.

\begin{tabular}{|c|c|c|c|c|c|c|c|c|}
\hline \multicolumn{9}{|c|}{ Pre- and Post-Referral Imaging } \\
\hline & $\begin{array}{l}\text { CT Thorax and } \\
\text { Abdomen }\end{array}$ & CT Abdomen & ${ }^{18}$ F-FDG-PET/CT & MRI Abdomen & $\begin{array}{l}\text { Transabdominal } \\
\text { Ultrasound }\end{array}$ & $\begin{array}{l}{ }^{64} \text { CuDotatate } \\
\text { or }{ }^{68} \text { GaDotatoc } \\
\text { PET/CT }\end{array}$ & CT Thorax & $\begin{array}{l}\text { 131 I-Meta-Iodbenzylguanidine } \\
\text { (MIBG) Scintigraphy }\end{array}$ \\
\hline Pre-referral & 54 & 31 & 27 & 10 & 9 & 6 & 3 & 0 \\
\hline Post-referral & 1 & 4 & 8 & 10 & 1 & 146 & 0 & 1 \\
\hline \multicolumn{9}{|c|}{ Pre-and post-referral endoscopic examinations } \\
\hline \multicolumn{4}{|c|}{ Colonoscopy } & \multicolumn{2}{|c|}{ Gastroscopy } & \multicolumn{2}{|c|}{ Capsule Endoscopy } & Endoscopic Ultrasound \\
\hline \multicolumn{2}{|c|}{ Pre-referral } & \multicolumn{2}{|c|}{33} & \multicolumn{2}{|c|}{27} & \multicolumn{2}{|c|}{12} & 1 \\
\hline
\end{tabular}




\subsection{Examinations Post-Referral}

In total 184 diagnostic examinations were performed post-referral, including $146{ }^{64} \mathrm{Cu}$-Dotatate or ${ }^{68} \mathrm{Ga}$-Dotatoc positron emission tomography (PET)/Computed tomography (CT) [29] (shown in Table 2). In 42 cases, no examination was performed post-referral for the following reasons: spontaneous normalization of plasma CgA concentrations post-referral $(n=20)$, normalization of CgA after discontinuation of PPI $(n=11)$, sufficient imaging performed pre-referral $(n=6)$, CgA PIA within the normal range $(n=5)$.

\subsection{Positive Predictive Value of Elevated CgA Prior to Referral}

Twenty-five patients were diagnosed with NET either prior to referral but after measurement of CgA $(n=7)$ or after workup in the NET Centre $(n=18)$. The primary location was the small intestine $(n=16)$, pancreas $(n=6)$, adrenals $(n=2)$ and stomach $(n=1)$. NET cases are shown in Table 3 . In patients with verified NET, CgA was within normal range (false negative) in six cases (24\%) and above URL (true positive) in 19 cases, corresponding to a sensitivity of $76 \%$. The sensitivity of an elevated CgA concentration was 50\% in cases with localized disease, $80 \%$ in cases with local lymph node metastases and $100 \%$ in cases with distant metastases (shown in Table 3).

Table 3. NET location and extent of disease. Total number of patients and number of patients with CgA levels within normal range are given.

\begin{tabular}{ccccc}
\hline & Total & Localized & Lymph Node Metastases & Distant Metastases \\
\hline Total (normal CgA) & $25(6)$ & $10(5)$ & $5(1)$ & $10(0)$ \\
Small intestine (normal CgA) & $16(2)$ & $2(1)$ & $4(1)$ & $10(0)$ \\
Pancreas (normal CgA) & $6(4)$ & $5(4)$ & $1(0)$ & 0 \\
Adrenals (normal CgA) & $2(0)$ & $2(0)$ & 0 & 0 \\
Stomach (normal CgA) & $1(0)$ & $1(0)$ & 0 & 0 \\
\hline
\end{tabular}

In 8 of 19 true positive cases, an elevated CgA contributed substantially to the NET suspicion. In the remaining 11 true positive cases, a suspected NET tumor was visualized by imaging $(n=10)$ or capsule endoscopy $(n=1)$ prior to CgA measurement.

The CgA concentrations were elevated without evidence of NET after workup in the NET Centre (i.e., false positive) in 148/197 cases (75\%). NET was diagnosed in 19/167 cases with elevated CgA plasma concentration at referral. Thus, the overall positive predictive value (PPV) of CgA was $11 \%$ and increased to $15 \%$ if patients treated with PPI were excluded (16/109). PPV increased to 67\% when the CgA plasma concentration was severely elevated, and patients treated with PPI were excluded. PPV of plasma CgA in patients treated with PPI was 5\%. None of the six patients with severely elevated plasma CgA concentration during PPI treatment were diagnosed with NET (PPVs are shown in Table 4).

Table 4. Positive predictive value of CgA depending on PPI status and level of CgA elevation.

\begin{tabular}{cccccc}
\hline & Total & $\mathbf{1 - 2} \times \mathbf{U R L}$ & $\mathbf{2 - 4} \times \mathbf{\text { URL }}$ & $\mathbf{4 - 8} \times \mathbf{\text { URL }}$ & $\mathbf{> 8 \times \text { URL }}$ \\
\hline $\begin{array}{c}\text { All elevated CgA plasma } \\
\text { concentrations (true elevated) } \\
\text { and PPV, } \%\end{array}$ & $\begin{array}{c}167(19) \\
11 \%\end{array}$ & $\begin{array}{c}91(5) \\
5 \%\end{array}$ & $\begin{array}{c}41(2) \\
5 \%\end{array}$ & $\begin{array}{c}20(6) \\
30 \%\end{array}$ & $\begin{array}{c}15(6) \\
40 \%\end{array}$ \\
\hline $\begin{array}{c}\text { Elevated CgA without PPI } \\
\text { true elevated) and PPV, } \%\end{array}$ & $109(16)$ & $68(4)$ & $19(2)$ & $13(4)$ & $9(6)$ \\
\hline $\begin{array}{c}\text { Elevated CgA with PPI (true } \\
\text { elevated) and PPV, } \%\end{array}$ & $61(3)$ & $23(1)$ & $22(0)$ & $7(2)$ & $67 \%$ \\
\hline
\end{tabular}

The plasma concentration of $\mathrm{CgA}$ was significantly associated with the risk of finding a NET; the OR was 1.12 per $100 \mathrm{pmol} / \mathrm{L}$ increase in plasma CgA concentration $(p<0.005)$. When excluding 
PPI-treated patients, the OR was $1.18(p<0.001)$. In patients treated with PPI, no significant association between CgA concentration and risk of NET was found-OR $0.96(p=0.74)$

Table 5 shows how frequently a NET was diagnosed per indication for CgA measurement. When the indication for CgA measurement was an examination (i.e., imaging or endoscopy) suggestive of NET, 44\% were diagnosed with NET. When CgA was measured because of GI symptoms 3\% were diagnosed with NET.

Table 5. Indications for CgA measurements, frequency of NET diagnosis and NET type.

\begin{tabular}{|c|c|c|c|}
\hline & Indication for $\mathrm{CgA}, n$ & NET Diagnosed, $n(\%)$ & $\begin{array}{c}\text { NET Type, Location, Extent of Disease and } \\
\text { CgA Level }\end{array}$ \\
\hline GI symptoms & 65 & $2(3 \%)$ & $\begin{array}{c}\text { Small intestine NET, distant metastases, } \\
\text { elevated CgA }(n=1) \\
\text { ECL'oma, stomach, localized, elevated CgA } \\
(n=1)\end{array}$ \\
\hline Attack-like phenomena & 41 & $3(7 \%)$ & $\begin{array}{l}\text { Pheochromocytoma, localized, elevated CgA } \\
\qquad(n=1) \\
\text { Insulinoma, localized, normal CgA }(n=1) \\
\text { Insulinoma, localized, elevated CgA }(n=1)\end{array}$ \\
\hline $\begin{array}{c}\text { Examination suggestive } \\
\text { of NET }\end{array}$ & 36 & $16(44 \%)$ & $\begin{array}{l}\text { Small intestine NET, localized, normal CgA } \\
\qquad(n=1) \\
\text { Small intestine NET, localized, elevated CgA } \\
\qquad(n=1) \\
\text { Small intestine NET, lymph node metastases, } \\
\text { normal CgA }(n=1) \\
\text { Small intestine NET, lymph node metastases, } \\
\text { elevated CgA }(n=3) \\
\text { Small intestine NET, distant metastases, } \\
\text { elevated CgA }(n=6) \\
\text { Pancreas NET, localized, normal CgA ( }(n=3) \\
\text { Pancreas NET, lymph node metastases, } \\
\text { elevated CgA }(n=1)\end{array}$ \\
\hline Flushing & 34 & $4(12 \%)$ & $\begin{array}{l}\text { Pheochromocytoma, localized, elevated CgA } \\
\qquad(n=1) \\
\text { Small intestine NET, distant metastases, } \\
\text { elevated CgA }(n=3)\end{array}$ \\
\hline Unspecific symptoms & 14 & 0 & \\
\hline Coincidental & 7 & 0 & \\
\hline
\end{tabular}

\subsection{Causes of Elevated CgA Apart From NET}

In 39 cases with falsely elevated $\mathrm{CgA}$, spontaneous normalization was observed between $\mathrm{CgA}$ measurements pre- and post-referral and in 19 cases comorbidity was identified as a possible cause of increased levels of CgA (renal dysfunction $n=10$; heart disease $n=4$; chronic atrophic gastritis $n=1$, multimorbidity $n=4)$.

CgA concentrations were elevated in 58/61 patients treated with PPI during pre-referral CgA measurements. When PPI was discontinued for at least 1 week, normalization of CgA was achieved in 28/46 cases. The average CgA concentration decreased from 445 (IQR 197-456) to 128 pmol/L (90-152) after discontinuation $(p<0.0001)$ (shown in Figure 3). 


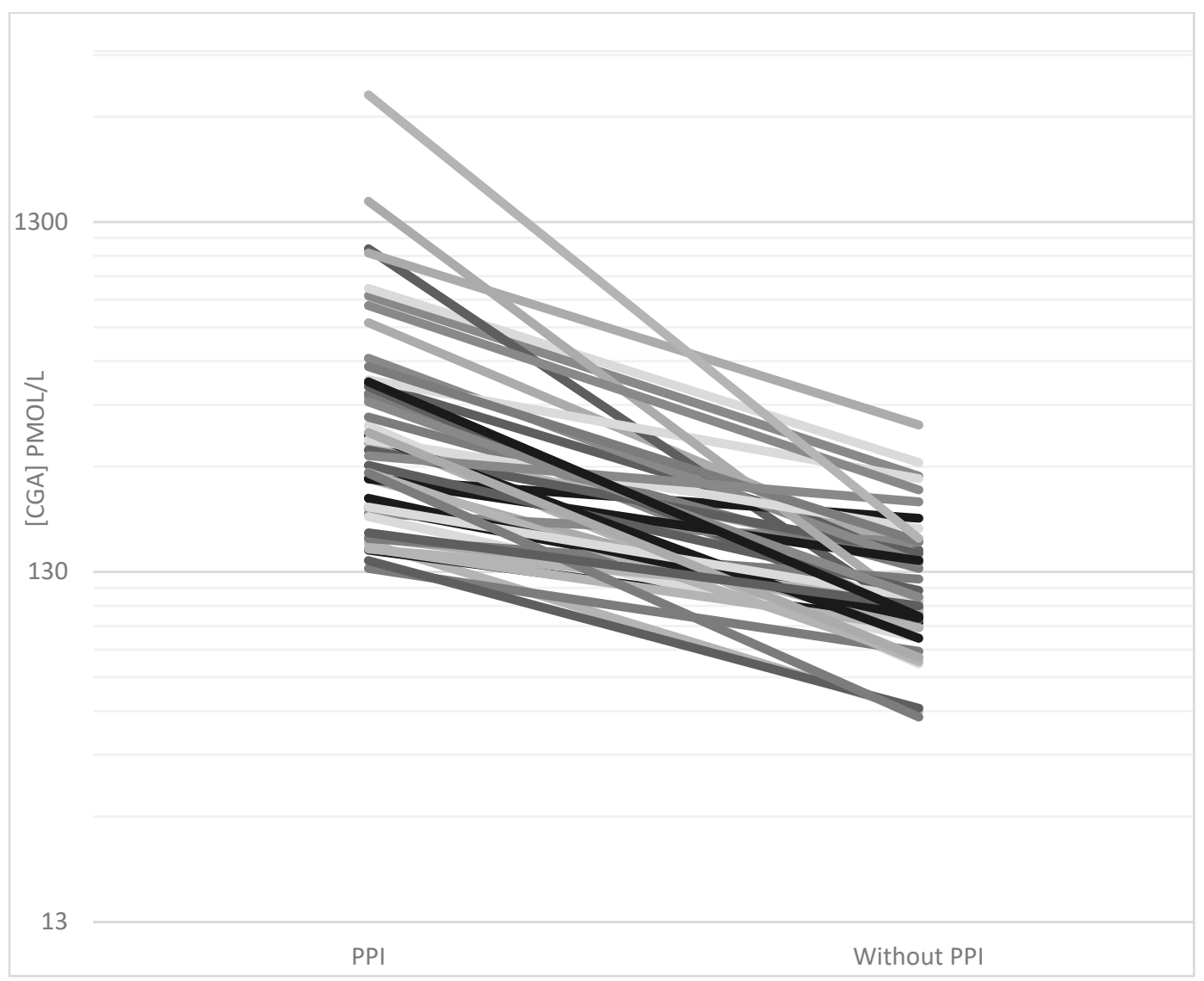

Figure 3. $\mathrm{CgA}$ plasma concentrations (pmol/L) in all patients with discontinued proton pump inhibitor (PPI) treatment. Plasma concentrations were measured using the $\mathrm{CgA}_{340-348}$ radioimmunoassay during PPI treatment (pre-referral) and after discontinuation of PPI for at least one week (post-referral).

Processing-independent analysis of CgA (CgA PIA) was performed in 47 cases with unexplained continuously elevated $\mathrm{CgA}$ concentrations. In 28 patients, the $\mathrm{CgA}$ PIA was within normal range while simultaneously $\mathrm{CgA}_{340-348}$ was still elevated. In the remaining 19 cases, simultaneous plasma $\mathrm{CgA}_{340-348}$ and CgA PIA were both elevated $(n=17)$ or within normal range $(n=2)$. CgA PIA within normal range was used to disprove NET suspicion in five cases without performing other examinations. The remaining 42 patients had a ${ }^{64} \mathrm{Cu}$-Dotatate or ${ }^{68} \mathrm{Ga}$-Dotatoc PET/CT performed with no sign of NET.

\section{Discussion}

The main results from the present study were that only a small fraction—around $11 \%$-of patients with elevated plasma CgA concentrations ended up with a histologically verified NET diagnosis after workup at a specialized tertiary center for diagnosing and treating G1 and G2 NETs. PPI treatment and differences in post-translational processing of $\mathrm{CgA}$ were identified as the most frequent causes of falsely elevated $\mathrm{CgA}$ concentrations. In accordance with previous studies, we found that normal $\mathrm{CgA}$ does not exclude NET, since 6 of 25 diagnosed patients did not have elevated plasma CgA [5,16].

In recent years, we have observed an increase in patients referred for NET workup with elevated concentrations of CgA. NET was only found in 19 out of 167 patients with elevated CgA. Furthermore, elevated CgA only contributed substantially to the NET diagnosis in eight of these cases since measurement of $\mathrm{CgA}$ in the remaining 11 cases was performed after imaging or endoscopy highly suggestive of NET. All patients with metastatic disease had elevated CgA concentrations whereas half of patients with localized disease had elevated $\mathrm{CgA}$, strengthening the idea that $\mathrm{CgA}$ is more sensitive in disseminated disease compared to localized disease [16-18,30,31]. PPI is a well-known 
cause of falsely elevated $\mathrm{CgA}[5,13,15,32]$, but even after excluding the substantial number of patients treated with PPI, the overall PPV of elevated CgA was only $15 \%$. The risk of NET was significantly associated with an increase in CgA plasma concentration and when plasma CgA was severely elevated, and PPI-treated patients were excluded, the PPV rose to $67 \%$. There was no association between an increase in $\mathrm{CgA}$ concentration and NET risk when patients were treated with PPI. Therefore, it is questionable whether an elevated CgA concentration during PPI treatment should be assigned any diagnostic value.

We identified several causes of falsely elevated CgA concentrations. Around one-third of all cases with elevated $\mathrm{CgA}$ were treated with PPI and normalization of CgA was achieved after pausing PPI in around half of these cases. Furthermore, it is likely that a longer pause of PPI would have resulted in the normalization of $\mathrm{CgA}$ in more cases since prolonged treatment with PPI causes enterochromaffin-like (ECL)-cell hyperplasia [33,34]. In patients who cannot discontinue PPI, H2 receptor antagonist (H2RA) replacement may be tried during one or two weeks of PPI discontinuation [35] as H2RA affects gastric acidity, gastrin and CgA levels to a lesser extent than PPI [36]. In 39 patients, CgA was spontaneously normalized between $\mathrm{CgA}$ measurements pre- and post-referral, probably reflecting biological variability. Two studies have been conducted regarding biological variation of $\mathrm{CgA}$ both supporting that within-subject variability could have caused marginally elevated $\mathrm{CgA}$, which would later normalize spontaneously [37,38]. In 19 cases, comorbidity was identified as a possible cause of increased levels.

As a novel approach, we measured CgA PIA in the patients with continuously unexplained elevated CgA concentrations in plasma. CgA PIA has demonstrated a high diagnostic accuracy (i.e., diagnostic sensitivity and specificity) compared to the $\mathrm{CgA}_{340-348}$ RIA and other $\mathrm{CgA}$ assays without trypsin cleavage prior to measurement $[14,18]$. In $60 \%$ of tested patients we found that CgA PIA was within normal range, while simultaneous $\mathrm{CgA}_{340-348}$ was still elevated, supporting a substantial improvement in diagnostic specificity. Thus, our data suggest that $\mathrm{CgA}$ PIA could be used to disprove NET suspicion based on elevated regular $\mathrm{CgA}$, hereby avoiding unnecessary examinations. The $\mathrm{CgA}$ PIA is a cumbersome analysis to perform, and therefore it can only be requested by our NET Centre. Our data emphasize that new biomarkers of NENs are highly warranted. Circulating tumor mRNA has been investigated but more data are needed before these new technics can be recommend for clinical use [18,39].

A substantial delay in the diagnosis of NETs has been reported $[7,40]$ highlighting the need for increased awareness of this rare type of tumor. Our data highlight the question of whether an increase in the use of diagnostic CgA measurement is the solution to this problem, since CgA measurements rarely contributed to the diagnosis and were most often falsely elevated. We therefore suggest that in case of symptoms suggestive of foregut NET (e.g., insulinoma or gastrinoma), the initial biochemical investigations should be restricted to the relevant specific hormone (e.g., insulin or gastrin). Regarding SI-NET, we observed that symptoms that could be associated with carcinoid syndrome rarely predicted NET. Therefore, we will argue against the routine use of plasma CgA measurement in patients with GI symptoms, flushing-like symptoms, or unspecific cancer symptoms. If a carcinoid tumor is suspected, we suggest performing a CT of the thorax and abdomen. SI-NETs rarely cause carcinoid syndrome before metastasizing to the liver, since the liver metabolizes bioactive molecules such as serotonin $[10,11]$. Therefore, a patient presenting with carcinoid syndrome most likely has disseminated disease with metastases visible on an abdominal CT. In alignment with this assumption, all SI-NETs were visualized when an abdominal CT prior to referral was performed ( 8 of 16 SI-NET patients-data not shown).

A strength of the present study is that it reflects the use of CgA in every day clinical practice in patients presenting with symptoms, which can be associated with NETs. Another strength is the extensive use of ${ }^{68} \mathrm{Ga}$-Dotatoc or ${ }^{64} \mathrm{Cu}$-Dotatate $\mathrm{PET} / \mathrm{CT}$, which was performed either prior to referral or predominantly in the NET Centre in more than $75 \%$ of patients. These imaging modalities are considered the most sensitive in diagnosing or excluding G1 and G2 NETs [29,41]. Furthermore, the same validated 
method and laboratory facilities were used for measurement of $\mathrm{CgA}$ in all analyses both pre- and post-referral. Our in-house $\mathrm{CgA}_{340-348}$ assay as well as the $\mathrm{CgA}$ PIA has recently been compared with eight commercially available kits in 130 well-characterized patients with SI-NETs. In terms of diagnostic accuracy, the in-house $\mathrm{CgA}_{340-348}$ RIA was superior to all commercial assays and in accordance with the results from the present study-the highest diagnostic accuracy was obtained with CgA PIA [18].

One limitation of this study is that we probably do not see the majority of true negative and maybe also false negative $\mathrm{CgA}$ measurements since a plasma $\mathrm{CgA}$ concentration within normal range presumably rarely leads to referral. This could lead to an overestimation of diagnostic sensitivity and an underestimation of diagnostic specificity. The negative predictive value and specificity of plasma $\mathrm{CgA}$ are undoubtfully much higher than what could be estimated based on our data and therefore these calculations have not been carried out.

In conclusion, our data do not support the use of $\mathrm{CgA}$ measurement as a screening tool in patients suspected of NET since the PPV was unacceptably low causing unnecessary examinations, delay in relevant examinations and worry for the patient. If a functional NET is suspected, we suggest measurement of relevant specific hormones and conducting relevant imaging. We observed a significant increase in the risk of finding a NET with increasing plasma concentration of $\mathrm{CgA}$, suggesting that considering the degree of $\mathrm{CgA}$ elevation is important when evaluating NET risk. PPI should always be paused for at least one week before measurement of $\mathrm{CgA}$ since little diagnostic value can be assigned to even highly elevated CgA plasma concentrations during PPI treatment. CgA PIA was often within normal range while $\mathrm{CgA}_{340-348}$ RIA was falsely elevated, suggesting that this method could be a way of disproving NET suspicion when it is based primarily on elevated regular CgA plasma concentrations.

Author Contributions: The study was conceptualized by J.B., M.A. and J.K.; Formal analysis: J.B.; Investigation:J.B., M.A.; Methodology: J.B., M.A., J.K., P.H., M.K., B.F., P.O., S.W.L., U.K., A.K., J.F.R. and L.H.; Project administration: J.B. and M.A.; Resources: M.A.; Supervision: M.A., J.K. and U.K.; Visualization: J.B., M.A., J.K., P.H., M.K., M.A., S.W.L., A.K., B.F., U.K., J.F.R. and L.H.; Writing-original draft: J.B. and M.A.; Writing-review and editing: J.B., M.A., J.K., P.H. and M.K., M.A., S.W.L., A.K., B.F., U.K., J.F.R. and L.H. All authors have read and agreed to the published version of the manuscript.

Funding: This study has not received any external funding.

Conflicts of Interest: The authors have no conflicts of interest to declare concerning this study.

\section{References}

1. Leoncini, E.; Boffetta, P.; Shafir, M.; Aleksovska, K.; Boccia, S.; Rindi, G. Increased incidence trend of low-grade and high-grade neuroendocrine neoplasms. Endocrine 2017, 58, 368-379. [CrossRef]

2. Nagtegaal, I.D.; Odze, R.D.; Klimstra, D.; Paradis, V.; Rugge, M.; Schirmacher, P.; Washington, M.K.; Carneiro, F.; Cree, I.A.; The WHO Classification of Tumours Editorial Board. The 2019 WHO classification of tumours of the digestive system. Histopathology 2019, 76, 182-188. [CrossRef]

3. Miettinen, M. Synaptophysin and neurofilament proteins as markers for neuroendocrine tumors. Arch. Pathol. Lab. Med. 1987, 111, 813-818.

4. Parbhu, S.K.; Adler, D.G. Pancreatic neuroendocrine tumors: Contemporary diagnosis and management. Hosp. Pract. 2016, 44, 109-119. [CrossRef]

5. Marotta, V.; Zatelli, M.C.; Sciammarella, C.; Ambrosio, M.R.; Bondanelli, M.; Colao, A.; Faggiano, A. Chromogranin A as circulating marker for diagnosis and management of neuroendocrine neoplasms: More flaws than fame. Endocr. Relat. Cancer 2018, 25, R11-R29. [CrossRef]

6. Cives, M.; Strosberg, J. Gastroenteropancreatic Neuroendocrine Tumors. CA Cancer J. Clin. 2018, 68, 471-487. [CrossRef]

7. Basuroy, R.; Bouvier, C.; Ramage, J. (John); Sissons, M.; Kent, A.; Srirajaskanthan, R. Presenting Symptoms and Delay in Diagnosis of Gastrointestinal and Pancreatic Neuroendocrine Tumours. Neuroendocrinology 2018, 107, 42-49. [CrossRef] 
8. Modlin, I.M.; Oberg, K.; Chung, D.C.; Jensen, R.T.; De Herder, W.W.; Thakker, R.V.; Caplin, M.; Fave, G.D.; Kaltsas, G.A.; Krenning, E.P.; et al. Gastroenteropancreatic neuroendocrine tumours. Lancet Oncol. 2008, 9,61-72. [CrossRef]

9. Guilmette, J.M.; Nosé, V. Neoplasms of the Neuroendocrine Pancreas. Adv. Anat. Pathol. 2019, 26, 13-30. [CrossRef]

10. Mota, J.M.; Sousa, L.G.; Riechelmann, R.P. Complications from carcinoid syndrome: Review of the current evidence. Ecancermedicalscience 2016, 10, 662. [CrossRef]

11. Fanciulli, G.; Nike, O.B.O.; Ruggeri, R.M.; Grossrubatscher, E.; Calzo, F.L.; Wood, T.D.; Faggiano, A.; Isidori, A.; Colao, A. Serotonin pathway in carcinoid syndrome: Clinical, diagnostic, prognostic and therapeutic implications. Rev. Endocr. Metab. Disord. 2020, 21, 599-612. [CrossRef]

12. Konecki, D.S.; Benedum, U.M.; Gerdes, H.H.; Huttner, W.B. The primary structure of human chromogranin A and pancreastatin. J. Biol. Chem. 1987, 262, 17026-17030.

13. Ardill, J.E.; O'Dorisio, T.M. Circulating Biomarkers in Neuroendocrine Tumors of the Enteropancreatic Tract: Application to Diagnosis, Monitoring Disease, and as Prognostic Indicators. Endocrinol. Metab. Clin. N. Am. 2010, 39, 777-790. [CrossRef]

14. Børglum, T.; Rehfeld, J.F.; Drivsholm, L.B.; Hilsted, L. Processing-Independent Quantitation of Chromogranin A in Plasma from Patients with Neuroendocrine Tumors and Small-Cell Lung Carcinomas. Clin. Chem. 2007, 53, 438-446. [CrossRef]

15. Gut, P.; Czarnywojtek, A.; Fischbach, J.; Bączyk, M.; Ziemnicka, K.; Wrotkowska, E.; Gryczyńska, M.; Ruchała, M. Chromogranin A-unspecific neuroendocrine marker. Clinical utility and potential diagnostic pitfalls. Arch. Med. Sci. 2016, 1, 1-9. [CrossRef]

16. Lyubimova, N.V.; Churikova, T.K.; Kushlinskii, N.E. Chromogranin As a Biochemical Marker of Neuroendocrine Tumors. Bull. Exp. Biol. Med. 2016, 160, 702-704. [CrossRef]

17. Jilesen, A.P.J.; Busch, O. (Olivier); Van Gulik, T.M.; Gouma, D.J.; Van Dijkum, E.J.N. Standard Pre- and Postoperative Determination of Chromogranin A in Resectable Non-Functioning Pancreatic Neuroendocrine Tumors-Diagnostic Accuracy: NF-pNET and Low Tumor Burden. Dig. Surg. 2014, 31, 407-414. [CrossRef]

18. Rehfeld, J.F.; Broedbaek, K.; Goetze, J.P.; Knigge, U.; Hilsted, L.M. True Chromogranin A concentrations in plasma from patients with small intestinal neuroendocrine tumours. Scand. J. Gastroenterol. 2020, 55, 565-573. [CrossRef]

19. Rehfeld, J.; Goetze, J.F.R.A.J.P. The Posttranslational Phase of Gene Expression: New Possibilities in Molecular Diagnosis. Curr. Mol. Med. 2003, 3, 25-38. [CrossRef]

20. Jensen, T.B.; Hilsted, L.; Rehfeld, J.F. Library of Sequence-specific Radioimmunoassays for Human Chromogranin A. Clin. Chem. 1999, 45, 549-560. [CrossRef]

21. Knigge, U.; Capdevila, J.; Bartsch, D.K.; Baudin, E.; Falkerby, J.; Kianmanesh, R.; Kos-Kudla, B.; Niederle, B.; Van Dijkum, E.N.; O'Toole, D.; et al. ENETS Consensus Recommendations for the Standards of Care in Neuroendocrine Neoplasms: Follow-Up and Documentation. Neuroendocrinology 2017, 105, 310-319. [CrossRef]

22. Fuksiewicz, M.; Kowalska, M.; Kolasińska-Ćwikła, A.; Ćwikła, J.B.; Sawicki, Ł.; Roszkowska-Purska, K.; Drygiel, J.; Kotowicz, B. Prognostic value of chromogranin A in patients with GET/NEN in the pancreas and the small intestine. Endocr. Connect. 2018, 7, 803-810. [CrossRef]

23. Dam, G.; Grønbæk, H.; Sorbye, H.; Evensen, E.T.; Paulsson, B.; Sundin, A.; Jensen, C.; Ebbesen, D.; Knigge, U.; Janson, E.T. Prospective Study of Chromogranin A as a Predictor of Progression in Patients with Pancreatic, Small-Intestinal, and Unknown Primary Neuroendocrine Tumors. Neuroendocrinology 2019, 110, 217-224. [CrossRef]

24. Niederle, B.; Pape, U.-F.; Costa, F.; Gross, D.; Kelestimur, F.; Knigge, U.; Öberg, K.; Pavel, M.; Perren, A.; Toumpanakis, C.; et al. ENETS Consensus Guidelines Update for Neuroendocrine Neoplasms of the Jejunum and Ileum. Neuroendocrinology 2016, 103, 125-138. [CrossRef]

25. Janson, E.T.; Sorbye, H.; Welin, S.; Federspiel, B.; Gronbaek, H.; Hellman, P.; Ladekarl, M.; Langer, S.W.; Mortensen, J.; Schalin-Jäntti, C.; et al. Nordic guidelines 2014 for diagnosis and treatment of gastroenteropancreatic neuroendocrine neoplasms. Acta Oncol. 2014, 53, 1284-1297. [CrossRef] 
26. González-Flores, E.; Serrano, R.; Sevilla, I.; Viúdez, A.; Barriuso, J.; Benavent, M.; Capdevila, J.; Jimenez-Fonseca, P.; López, C.; Garcia-Carbonero, R. SEOM clinical guidelines for the diagnosis and treatment of gastroenteropancreatic and bronchial neuroendocrine neoplasms (NENs) (2018). Clin. Transl. Oncol. 2018, 21, 55-63. [CrossRef]

27. Bardram, L.; Rehfeld, J.F. Processing-independent radioimmunoanalysis: A general analytical principle applied to progastrin and its products. Anal. Biochem. 1988, 175, 537-543. [CrossRef]

28. Tramonti, G.; Ferdeghini, M.; Annichiarico, C.; Norpoth, M.; Donadio, C.; Bianchi, R.; Bianchi, C. Relationship between renal function and blood level of chromogranin A. Ren. Fail. 2001, 23, 449-457. [CrossRef]

29. Johnbeck, C.B.; Knigge, U.; Loft, A.; Berthelsen, A.K.; Mortensen, J.; Oturai, P.; Langer, S.W.; Elema, D.R.; Kjaer, A. Head-to-Head Comparison of $64 \mathrm{Cu}$-DOTATATE and 68 Ga-DOTATOC PET/CT: A Prospective Study of 59 Patients with Neuroendocrine Tumors. J. Nucl. Med. 2016, 58, 451-457. [CrossRef]

30. Nehar, D.; Lombard-Bohas, C.; Olivieri, S.; Claustrat, B.; Chayvialle, J.-A.; Penes, M.-C.; Sassolas, G.; Borson-Chazot, F. Interest of Chromogranin A for diagnosis and follow-up of endocrine tumours. Clin. Endocrinol. 2004, 60, 644-652. [CrossRef]

31. Nikou, G.C.; Marinou, K.; Thomakos, P.; Papageorgiou, D.; Sanzanidis, V.; Nikolaou, P.; Kosmidis, C.; Moulakakis, A.; Mallas, E. Chromogranin A Levels in Diagnosis, Treatment and Follow-Up of 42 Patients with Non-Functioning Pancreatic Endocrine Tumours. Pancreatology 2008, 8, 510-519. [CrossRef]

32. Waldum, H.L.; Sørdal, Ø.F.; Mjønes, P.G. The Enterochromaffin-like [ECL] Cell-Central in Gastric Physiology and Pathology. Int. J. Mol. Sci. 2019, 20, 2444. [CrossRef]

33. Bektas, M.; Saraç, N.; Cetinkaya, H.; Törüner, M.; Erdemli, E.; Keskin, O.; Soykan, I.; Oktay, E.I.; Korkut, E.; Ustün, Y.; et al. Effects of Helicobacter pylori infection and long-term proton pump inhibitor use on enterochromaffin-like cells. Ann. Gastroenterol. 2012, 25, 123-127.

34. Lundell, L.; Vieth, M.; Gibson, F.; Nagy, P.; Kahrilas, P.J. Systematic review: The effects of long-term proton pump inhibitor use on serum gastrin levels and gastric histology. Aliment. Pharmacol. Ther. 2015, 42, 649-663. [CrossRef]

35. Korse, C.M.; Muller, M.; Taal, B.G. Discontinuation of proton pump inhibitors during assessment of chromogranin A levels in patients with neuroendocrine tumours. Br. J. Cancer 2011, 105, 1173-1175. [CrossRef]

36. Lanzon-Miller, S.; Pounder, R.E.; Hamilton, M.R.; Ball, S.; Chronos, N.A.F.; Raymond, F.; Olausson, M.; Cederberg, C. Twenty-four-hour intragastric acidity and plasma gastrin concentration before and during treatment with either ranitidine or omeprazole. Aliment. Pharmacol. Ther. 2007, 1, 239-251. [CrossRef]

37. Braga, F.; Ferraro, S.; Mozzi, R.; Dolci, A.; Panteghini, M. Biological variation of neuroendocrine tumor markers chromogranin A and neuron-specific enolase. Clin. Biochem. 2013, 46, 148-151. [CrossRef]

38. Dittadi, R.; Meo, S.; Gion, M. Italian Committee for the Quality Control in the Oncology L, Italian Network for Quality Assessment of Tumor B. Biological variation of plasma chromogranin A. Clin. Chem. Lab. Med. 2004, 42, 109-110.

39. Modlin, I.M.; Kidd, M.; Malczewska, A.; Drozdov, I.; Bodei, L.; Matar, S.; Chung, K.-Y. The NETest: The Clinical Utility of Multigene Blood Analysis in the Diagnosis and Management of Neuroendocrine Tumors. Endocrinol. Metab. Clin. N. Am. 2018, 47, 485-504. [CrossRef]

40. Basuroy, R.; Bouvier, C.; Ramage, J.K.; Sissons, M.; Srirajaskanthan, R. Delays and routes to diagnosis of neuroendocrine tumours. BMC Cancer 2018, 18, 1122. [CrossRef]

41. Zhang, P.; Yu, J.; Li, J.; Shen, L.; Li, N.; Zhu, H.; Zhai, S.; Zhang, Y.; Yang, Z.; Lu, M. Clinical and Prognostic Value of PET/CT Imaging with Combination of 68Ga-DOTATATE and 18F-FDG in Gastroenteropancreatic Neuroendocrine Neoplasms. Contrast Media Mol. Imaging 2018, 2018, 2340389. [CrossRef]

Publisher's Note: MDPI stays neutral with regard to jurisdictional claims in published maps and institutional affiliations. 